\title{
Inadequate management of hyperlipidaemia after coronary bypass surgery shown by medical audit
}

\author{
David B Northridge, Amal Shandall, Alan Rees, Maurice B Buchalter
}

\begin{abstract}
Objective-To audit the detection and management of hyperlipidaemia in patients who have had coronary bypass surgery.

Patients-100 consecutive patients (81 men), mean age 61 , who had survived at least 3 months after coronary bypass surgery.

Methods-Retrospective review of case notes and computerised biochemistry records.

Results-83 patients had at least one lipid measurement in the hospital, and of the remaining 17 patients, 10 had undergone urgent or emergency surgery. The median (range) total cholesterol was 6.7 $(4 \cdot 0-11 \cdot 7) \mathrm{mmol} / \mathrm{l}$ and the triglyceride concentration was $2 \cdot 1(0 \cdot 6-18 \cdot 4) \mathrm{mmol} / \mathrm{l}$. Only 30 patients were referred to a dietician, and 12 were given a lipid lowering drug-these interventions were no more frequent in patients with a cholesterol concentration above than below the median.

Conclusions-Although a high proportion of patients who undergo routine coronary bypass surgery have their plasma lipid concentrations measured, many patients with raised cholesterol concentrations, who would benefit from lipid lowering interventions, are not offered them.
\end{abstract}

(Br Heart f 1994;72:466-467)

While the long running debate over the value of lipid lowering treatment for the primary prevention of ischaemic heart disease rages on, ${ }^{12}$ most authorities agree on the value of secondary prevention in patients with established disease. Patients at highest risk of coronary events stand to gain the most, ${ }^{3}$ so the recently published guidelines of the British Hyperlipidaemia Association suggest that patients with established ischaemic heart disease, particularly those who have had revascularisation procedures, should be amongst the highest priority for treatment, aiming to reduce total serum cholesterol to $<5 \cdot 2 \mathrm{mmol} / 1$ and low density lipoprotein cholesterol to $<3.4 \mathrm{mmol} / 1 .{ }^{4}$

There is strong evidence to support this approach in patients who have had coronary bypass surgery, as $>50 \%$ of saphenous vein grafts are considerably stenosed or occluded within 10 years of the operation and the single most important predictor of vein graft failure is hyperlipidaemia. ${ }^{5}$ Furthermore, in a randomised placebo controlled study of 162 patients after coronary bypass surgery, drug treatment that reduced the mean total cholesterol from 6.35 to $4.65 \mathrm{mmol} / 1$, also reduced the incidence of new vein graft lesions at angiographic follow up after two and four years. ${ }^{67}$ We therefore undertook a medical audit to determine current practice in patients who have had coronary bypass surgery at the University Hospital of Wales.

\section{Patients and methods}

The case notes of 100 consecutive patients who had had coronary bypass surgery under the care of one of three cardiac surgeons were reviewed by a single investigator (AS). Patients are reviewed routinely by their surgeon six weeks after the operation, and the referring cardiologist 12 weeks after the operation, so the audit was conducted after this clinical review process. Plasma triglycerides and total cholesterol were determined after an overnight fast at the time of cardiac catheterisation. Extensive measures were taken to detect any lipid measurements either filed or hand written in the notes or in the computerised biochemistry records. The case notes of patients with no lipid measurement, and a $10 \%$ sample of the rest, were checked by a second investigator. Eight of the hundred patients had more than one recorded lipid measurement, and for the purposes of this audit the earliest measurement, which was before surgery in every case, was taken to be representative for that patient.

\section{Results}

There were 81 men and 19 women and the mean (range) age was 61 (44-78). The total number of patients with a recorded lipid measurement, either in the notes or from biochemistry records, was 83 . Of the 17 patients with no lipid record, 10 had had urgent or emergency surgery. The median (range) total cholesterol was $6.7(4 \cdot 0-11 \cdot 7) \mathrm{mmol} / \mathrm{l}$, and the median triglyceride concentration was $2 \cdot 1$ $(0.6-18.4) \mathrm{mmol} / \mathrm{l}$. These results were included in either the cardiac or cardiac surgery discharge summary in only $36(43 \%)$ of the cases in whom they were measured. 
Proportions of patients referred to a dietician or given a lipid lowering drug by the total cholesterol concentration

\begin{tabular}{lrr}
\hline & \multicolumn{2}{c}{ Total cholesterol } \\
\cline { 2 - 3 } & $<6.7$ & $>6.7$ \\
\hline No & 42 & \multicolumn{1}{c}{41} \\
Referred to a dietieian (n(\%)) & $18(43)$ & $12(29)$ \\
Prescribed lipid lowering drug (n(\%)) & $4(10)$ & $8(19)$ \\
\hline
\end{tabular}

Differences between patients above and below the median cholesterol were not significant $\left(\chi^{2}\right)$.

The table shows the effects of plasma lipid results on the management of patients. Thirty patients $(36 \%)$ were referred to a dietician, and those with a total cholesterol above the median were no more likely to be referred than those below the median. Twelve patients (14\%) were given specific lipid lowering drug treatment, including eight of the patients with a total cholesterol above the median. Sixteen high risk patients were identified who had a total cholesterol $>8 \mathrm{mmol} / \mathrm{l}$, of whom only four were treated with lipid lowering drugs. These patients had more severe coronary disease-three had a left main stenosis and seven had unstable symptoms.

\section{Discussion}

This audit shows that although a high proportion of patients who undergo routine coronary bypass surgery have their plasma lipid concentrations measured, many patients with high total cholesterol concentrations, who would benefit from lipid lowering interventions, are not offered them. A similar reluctance to treat patients with established ischaemic heart disease and hyperlipidaemia was shown by a recent audit of cardiological practice in a New York metropolitan teaching hospital. ${ }^{8}$ Out of a total of 81 patients with ischaemic heart disease who were interviewed after coronary angiography, only 14 patients $(17 \%)$ were actively treated with a cholesterol lowering diet or drugs. Furthermore there was little evidence of targeting these interventions to patients at highest risk. Only three out of 30 patients with a total cholesterol $>6.5 \mathrm{mmol} / \mathrm{l}$, and only 11 out of 40 patients who underwent a coronary revascularisation procedure were receiving cholesterol lowering treatment.

This audit shows that there are many possible reasons for the conservative treatment of hyperlipidaemia in patients who have had coronary bypass surgery. They may include a lack of appreciation of the different outcomes in secondary as opposed to primary prevention trials, insufficient time to provide preventive counselling, reluctance to prescribe lipid lowering drugs, and a lack of consensus concerning the roles of the cardiologist, cardiac surgeon, and general practitioner in secondary prevention. As a direct result of this audit local guidelines for the detection and management of hyperlipidaemia have been formulated and implemented. If these findings are typical of other cardiac centres then active measures are needed urgently to increase awareness of the importance of secondary prevention among all of the professionals involved in the care of patients after coronary bypass surgery.

1 Oliver MF. Doubts about preventing coronary disease. $B M F$ 1992;304:393-4.

2 Durrington PN. Can any agreement be reached on cholesterol lowering? Br Heart fु 1994;71:125-8.

3 Davey Smith G, Song F, Sheldon TA. Cholesterol lowering and mortality: the importance of considering initial level of risk. $B M \mp$ 1993;306:1367-70.

4 Betteridge DJ, Dodson PM, Durrington PN, Hughes EA, Laker MF, Nicholls DP, et al. Management of hyperlipidaemia: guidelines of the British Hyperlipidaemia Association. Postgrad Med $\mathcal{f}$ 1993;69:359-69.

5 Campeau L, Enjalbert M, Lesperance J, Bourassa MG, Kwiterovitch P Jr, Wacholder S, Sniderman A. The Kwiterovitch $\mathrm{P}$ Jr, Wacholder relation of risk factors to the development of atherosclerosis in saphenous vein bypass grafts and the progression of disease in the

6 Blankenhorn DH, Nessim SA, Johnson RL, Sanmarco ME, Azen SP, Cashin-Hemphill L. Beneficial effects of combined colestipol-niacin therapy on coronary atherosclerosis and coronary venous bypass grafts. $\mathcal{F} A M A$ 1987;257:3233-40

7 Cashin-Hemphill L, Mack WJ, Pogoda JM, Sanmarco ME, Azen SP, Blankenhorn DH. Beneficial effects of colestipol-niacin therapy on coronary atherosclerosis: a 4-year follow-up. $\mathcal{F} A M A 1990 ; 264: 3013-7$.

8 Cohen MV, Byrne MJ, Levine B, Gutowski T, Adelson R. Low rate of treatment of hypercholesterolemia by cardiologists in patients with suspected and proven coronary artery disease. Circulation 1991;83:1294-304. 